\title{
CHATS NA WEB: A LINGUAGEM PROIBIDA E A QUEDA DE TABUS ${ }^{*}$
}

Júlio César Araújo**

\begin{abstract}
Resumo: Neste artigo, discuto a suposição de que a linguagem proibida e os tabus a ela associados se dissolvem quando adentram o ambiente digital dos chats. A discussão é guiada pelas perspectivas sociolingüística de Preti (1983, 1992, 2000, 2001) e enunciativa de Benveniste ([1974] 1989), uma vez que esses trabalhos auxiliam aqui a analisar fragmentos de interação via chat, sendo, neste caso, considerados os vocábulos que se associam à gíria, à obscenidade, à blasfêmia, ao palavrão e à grosseria, sejam eles utilizados nos nicknames dos internautas ou na conversação. A análise dos fragmentos permite concluir que o anonimato conferido aos participantes, através dos seus apelidos, mostra-se como um dos fatores mais produtivos para o "livre" uso da linguagem marginal, a qual parece estar circunscrita não somente aos limites do verbal, mas também a outras semioses utilizadas pelos usuários.
\end{abstract}

Palavras-chave: chat; tabu lingüístico; interação lingüística; internet.

\section{INTRODUÇÃO}

Por que certas palavras pronunciadas face a face são proibidas em determinados grupos sociais? Por que o seu uso se transforma em um grave ato de violação de ritos? Como chamar a essa violação: grosseria? palavrão? blasfêmia? obscenidade? Questões como essas têm atraído o interesse acadêmico de lingüistas, os quais, à luz de suas análises, têm

\footnotetext{
* Uma versão anterior deste artigo foi apresentada ao PPGL-UFC como requisito para uma das qualificações do curso de Doutorado em Lingüística. Neste sentido, agradeço a Profa. Dra. Márcia Nogueira (UFC) que, sendo coordenadora do PPGL na época da qualificação, mediou o processo para que eu cumprisse essa estapa de minha formação acadêmica. Agradeço ainda aos pesquisadores que, na época, foram os pareceristas: Dr. Luciano Pontes (UECE), Dra. Edair Goski (UFSC) e Dra. Izete Coelho (UFSC), pela leitura atenta e contribuições dadas. Assumo a responsabilidade pelos problemas remanescentes.

** Professor da Universidade Federal do Ceará. Doutor em Lingüística. E-mail: <araujo@ufc.br>.
} 
mostrado que, de acordo com determinados grupos sociais, certas palavras "não deve[m] passar pela boca" (BENVENISTE, [1974] 1989, p. 260). Por outro lado, quando o homem sofre "uma proibição imposta de fora (por uma autoridade) e dirigida contra os [seus] desejos mais intensos", ele está diante de um tabu.

Que força misteriosa tem as palavras que geram essas proibições? Haveria alguma contra força que poderia, senão neutralizar, pelo menos atenuar tais proibições? Se a linguagem tem um entorno sócio-cultural, é razoável responder positivamente a essas perguntas, pois, na verdade, as instâncias discursivas em que nos inserimos influenciam poderosamente nosso projeto de dizer. Com base nisso, neste trabalho, analiso fragmentos de interações de chats, abrigando sob o rótulo de linguagem proibida ou marginal todos os vocábulos que se associam à gíria, à obscenidade, à blasfêmia, ao palavrão e à grosseria, sejam eles utilizados nos nicknames dos internautas ou na conversação realizada nesses ambientes virtuais. A questão que o orienta é como se caracteriza a linguagem proibida e os tabus a ela associados no ambiente digital das salas de chats?

Para esse intento, subseqüentemente discuto a noção de proibido à luz dos estudos sociolingüísticos de Preti (1983, 1992, 2000) e Monteiro (1986), e dos estudos enunciativos de Benveniste ([1974] 1989), para em seguida examinar índices do "livre uso" de uma "linguagem proibida" que parece se dissolver no ambiente digital dos chats.

\section{EM TORNO DA NOÇÃO DE PROIBIDO}

O medo de quebrar a fronteira do que é considerado permitido e do que é considerado proibido gera o que a sociedade denomina de tabu, porque as sanções sociais, previstas para quem adentra este terreno, são coercitivas.

Um estudioso que trabalha a noção do proibido na linguagem é Preti (1983), para quem o léxico é um "campo difícil de análise". Por pensar assim, ele chega a afirmar que "o léxico é o campo da língua que melhor espelha a dinâmica social” (PRETI, 1992, p. 93). Isto significa 
que a palavra reflete os valores culturais da sociedade, de modo que os julgamentos e os tabus que permeiam as práticas sociais são refletidos em um conjunto de vocábulos específicos: as palavras-tabu.

Esses lexemas específicos, segundo a concepção defendida por Preti (1983), estão inseridos no universo do erótico, o que, em meu entender, não se trata de uma regra, mas de uma delimitação para o seu estudo, pois as palavras-tabu pertencem também ao campo semântico da religião ${ }^{1}$. Além desse campo, em relação a doenças também há palavras/expressões proibidas, como a substituição de câncer por C.A., por exemplo.

Se for verdade que a quebra das convenções permite a materialidade lingüística dos tabus, então é razoável a afirmação de que tal subversão gera uma linguagem proibida, sobretudo "porque os juízos da sociedade [...] se transferem para o léxico" (PRETI, 1983, p. 61). Ao defender essa tese, Dino Preti mostra que quanto mais a relação léxico/costume ocorre na atmosfera do erótico, mais proeminente é a proibição de certos termos voltados para esse universo semântico, haja vista ser possível elencar muitas palavras que denotem tal relação ${ }^{2}$.

A fim de apresentar uma sistematicidade para a realização de um estudo desta natureza, Preti apresenta três aspectos nos quais se pode ancorar a pesquisa acerca da linguagem vista como proibida. Trata-se do vocábulo obsceno, do vocábulo gírio e do vocábulo comum marcado. Destes, focalizarei somente os dois primeiros, posto que neles reside o interesse do presente artigo, que é o de verificar como se caracteriza a linguagem proibida no ambiente digital dos chats.

\section{O VOCÁBULO OBSCENO E SEUS DESDOBRAMENTOS}

Para trabalhar o conceito de obscenidade, Preti (1983) usa, além do rótulo "obsceno", outros termos que gravitam ao seu redor, como a

\footnotetext{
${ }^{1}$ Chamar pelo Diabo em algumas crenças é vetado. Chama-se o Diabo de Inimigo, por exemplo.

${ }^{2}$ Segundo o autor, uma pesquisa inscrita nessa perspectiva não pode deixar de assumir um caráter sociolingǘstico, pois, de acordo com os seus argumentos, um estudo sobre tabus lingüísticos permite a depreensão e o controle de variáveis, tais como o prestígio social, a classe social, o contexto social, etc.
} 


\section{4}

blasfêmia, o palavrão e a grosseria. Para fins de organização, primeiro examinarei o que o autor entende por obsceno e por blasfêmia, para em seguida apresentar sua discussão sobre os conceitos de palavrão e grosseria. Apresentarei o pensamento de Preti e Benveniste, estabelecendo um diálogo entre ambos os autores.

Para Preti (1983, p. 62), penetrar no terreno da obscenidade na linguagem é inserir-se "no controvertido campo da moral das palavras". É possível falar em "moral das palavras" porque a elas são dados "valores" pelos enunciadores que passam a reconhecer em suas pronúncias o que ela representa. Houve um tempo em que se acreditou que esses "valores" atribuídos às palavras proibidas eram oriundos de uma classe social menos abastada. Porém, segundo os estudos de Preti, não é possível reduzir a circulação de palavras obscenas somente às práticas linguageiras incultas, posto que é possível verificar o gosto pela obscenidade entre os que pertencem à dita "classe nobre".

Quanto à relação comportamento/linguagem proibida e intimidade, é interessante perceber, a partir de Komesu (2005, p. 81), que, em tempos de reality shows, como os populares Big Brother Brasil (BBB) da Rede Globo, o proibido passa a ser matéria de publicização do que antes as pessoas faziam questão de ocultar. A autora também nos fala de um paradoxo contemporâneo ao se referir às câmeras espalhadas pelo país, como parte de um sistema de segurança, e aos reality shows, que jogam com a valorização do que é íntimo: "a sociedade que usa câmeras para se divertir com a banalidade do cotidiano alheio é a mesma que as emprega em sistemas de vigilância legitimados pela própria sociedade". Programas de TV, como o supracitado, oportunizam a desmistificação de alguns tabus lingüísticos, o que permite o avanço da destabuização de determinados termos. Os reality shows são apenas um dos muitos exemplos que servem para corroborar a crítica de Preti, segundo a qual, a classe social não é uma variável segura para se delimitar um estudo acerca da linguagem proibida.

A afirmação que conclui o parágrafo anterior é razoável se for considerado que a maioria das pessoas selecionadas para protagonizar a banalidade corriqueira de suas vidas neste tipo de programa não são, via de regra, de classes menos privilegiadas. O que não deve significar que são pessoas que tiveram acesso a uma educação escolar satisfatória, ainda que pertençam à classe média. No caso do BBB, por exemplo, há uma 
reunião de pessoas de várias partes do país, fato que permite uma rica troca entre os diversos falares. Em meio a essa geografia lingüística, a intimidade flagrada pelo olhar eletrônico das câmeras é tornada pública, dada à veiculação do programa em cadeia nacional, além de todos os telespectadores parecerem esperar exatamente a publicização, fora da casa do $\mathrm{BBB}$, do que seria proibido. Por esta razão, alguns usos de vocábulos obscenos se tornam cada vez menos tabuizados, já que ganham a simpatia do público, mesmo que o escatológico e o erótico sejam, constantemente, material utilizado para a sua produção. Nesta esteira, ainda que o trabalho de Preti (1983) não seja contemporâneo dos reality shows, suas formulações ajudam para que se construa uma compreensão sobre o fenômeno do proibido ser flagrado pelas câmeras, que representam o olhar curioso de cada telespectador.

Se de um lado não se pode afirmar que esses programas ajudam na diminuição de coerções sociais em relação a algumas palavras/expressões proibidas porque faltam pesquisas que dêem alguma sustentação a isso, de outro não é possível ignorar que o fato de todos poderem "espiar" a cotidianidade daquelas pessoas contribui para a aceitação de alguns termos, antes tidos como proibidos, "pois o crescente processo desmistificador do sexo [nestes programas] tem alargado ainda mais o uso da linguagem obscena, hoje comum até como índice de coloquialismo" (PRETI, 1983, p. 63) ${ }^{3}$.

Quanto a isso, em 1975, ao escrever sobre a criatividade lexical, Guilbert já preconizava esse "esvaziamento" do proibido, pois segundo suas palavras "os tabus sexuais e escatológicos se enfraquecem a ponto de esses termos penetrarem no dicionário com todas as letras. Parece que o vulgarismo não suscita mais um sentimento de horror, ao menos nas situações de comunicação entre familiares" (p. 87). Entre os sociolingüistas é consenso que o esvaziamento semântico de determinadas palavras-tabu não acontece como por milagre, mas está

\footnotetext{
${ }^{3}$ Não estou querendo ser simplista a ponto de afirmar que o mero fato de os participantes dos reality shows usarem uma linguagem obscena na TV contribui para a aceitação desses termos. Compreendo que há necessidade de maior tempo para os tabus irem sendo quebrados, pois tudo que diz respeito a novos costumes, tanto sociais como lingüísticos, demora muitos anos para acontecer. Não obstante, é relevante admitir a suposição de que determinados espaços discursivos, como os forjados pela TV e a Internet, podem apressar a naturalização dos termos-tabu, mesmo que se considere o fato de que a TV reproduz um comportamento que já está, de certa forma, difundido na sociedade.
} 
profundamente vinculado à relação língua/sociedade. Esta afirmação se justifica se pensarmos que os tabus desaparecem na linguagem porque desaparecem também nas relações sociais. A mulher, por exemplo, fala mais "palavrões" hoje em dia porque ocupa novos espaços e protagoniza novas relações sociais. Ela hoje vai para a rua, concorre com o homem; portanto, em algumas situações, pode falar igual a ele, o que não significa dizer que ela não sofre mais nenhum tipo de interdição (cf. ALMEIDA; ZAVAM, 2004, p. 248).

Sobre a blasfêmia, entendo, ao modo de Benveniste ([1974] 1989, p. 259), que ela constitui um tipo de léxico relacionado à moral e à religião, fato que a distancia do conceito de obscenidade, apresentado acima. Ao discutir o vocábulo blasfêmico, Benveniste parece imprimir certa hierarquia às palavras, pois estabelece uma distinção entre a blasfêmia e a imprecação. A última é considerada "a expressão blasfêmica por excelência, inteiramente distinta da blasfêmia como asserção difamante relativamente à religião ou à divindade" ". Assim, o autor vê dois tipos de blasfêmias: uma ligada à religião e à moral e a outra designada de imprecação. Esta última

não transmite nenhuma mensagem, ela não abre diálogo, não suscita resposta, a presença de um interlocutor nem mesmo é necessária. Ela não descreve também aquele que a emite. Este se trai mais do que se revela. A imprecação lhe escapa, é uma descarga emotiva. No entanto, esta descarga se realiza em fórmulas fixas, inteligíveis e descritíveis. (BENVENISTE, [1974] 1989, p. 261)

Como é possível observar, Benveniste assegura que a imprecação, compreendida como a apoteose da blasfêmia, embora apresente seu sentido isolado do contexto, é esvaziada de sua função comunicativa, porque é pronunciada sempre em função da pressão de um sentimento violento, vivido por alguém. Retornando ao caso dos reality shows, podese dizer que uma das vias de publicização da linguagem proibida se refere às imprecações, pois o confinamento e os princípios ardilosos daquele "jogo" podem propiciar várias "descargas emotivas" e, por isso, os

\footnotetext{
${ }^{4}$ Outro modo de estudar a blasfêmia pode ser através da oposição entre blasphemeo e euphemeo. A esse respeito, conferir o trabalho de Monteiro (1986, p. 21), o qual salienta que "a blasfêmia [...] sempre foi uma questão de linguagem [uma vez que] a própria noção de pecado, na interpretação eclesiástica, não se restringe às ações comportamentais: inclui também os pensamentos e as palavras".
}

ARAÚJO - Chats na web... 
atores envolvidos naquela situação sócio-discursiva se expõem para o grande público ao se trair por suas imprecações.

Quanto ao palavrão, Preti (1983) o define como um vocábulo catártico, dado o seu poder de aliviar as tensões com as quais convive o homem moderno. Neste ponto, parece que estamos diante de uma mesma definição para duas manifestações de linguagem proibida. Enquanto Benveniste defende que a imprecação, considerada um tipo de vocábulo blasfêmico, é reconhecida pela catarse que a descarga emotiva provoca em quem a profere/escreve, Preti (1983) assume a mesma definição para o palavrão. Se o traço fônico aproxima essas duas manifestações de linguagem proibida, talvez fosse possível dizer que o traço semântico serviria para diferenciar o palavrão da blasfêmia, pois esta estaria ligada à religião. Seguindo este raciocínio, pode-se dizer que há blasfêmia quando o vocábulo estiver associado a algo que é proibido porque ofende ou apresenta uma inverdade contra Deus. Assim, para os cristãos, por exemplo, dizer que Deus erra e é perverso porque não ama seus filhos é uma blasfêmia, e não um palavrão.

Outra manifestação da linguagem proibida é o vocábulo conhecido por grosseria. Este conceito parece não estar bem delimitado no trabalho de Preti (1983, p. 63), já que, segundo as suas explicações, "os termos grosseiros coincidem com um tom mais forte, que lhes acentua o caráter agressivo, tornando-se um veículo de expressão de sentimentos, muito mais do que de comunicação". Do ponto de vista fonético, o que se percebe é que tanto a imprecação - um tipo de blasfêmia - quanto o palavrão e a grosseria compartilham da mesma característica: o som catártico. Preti é conhecedor dessa dificuldade e, por isso, recorre a Guiraud (1976) para tentar resolver a indefinição. A proposta do francês citado assegura que a obscenidade e a grosseria podem ser distinguidas pelo conteúdo, o que, segundo demonstra Preti, não clarifica nada, uma vez que também o contexto e as limitações de uma cultura podem lançar luzes sobre essa indefinição.

Mas, há ainda de se considerar que nem sempre o obsceno e o grosseiro se deixam mostrar no conteúdo ou no contexto, pois a identificação do que é proibido, seja no palavrão, na obscenidade ou na grosseria, pode ser escamoteada em junturas fonéticas criativamente articuladas, as quais só se dão a perceber pelo material fônico de uma música de forró, por exemplo. Foi o que percebeu Aragão (1997, p. 89) 


\section{8}

ao estudar as músicas de forró, em que somente pela análise de estratégias semio-fonéticas utilizadas pelos compositores pôde observar as conotações proibidas. Depois de uma análise de várias letras de forró, a autora concluiu que

não se percebe qualquer problema de significação, de conotação ou duplo sentido. Contudo, ao se ouvirem as letras cantadas pode-se ver que essas letras tomam novos sentidos, com conotações de ordem erótico-sensual, a partir do jogo fonéticosemântico que os autores fazem, utilizando-se de possibilidades estruturais e combinatórias que o sistema permite.

Mesmo que flagrar a ocorrência do proibido não seja tão simples, pois este pode estar escamoteado, Preti (1983, p. 65), para mostrar a equivalência entre alguns dos termos discutidos nesta seção, ressalta que "um dos índices do vocábulo grosseiro e obsceno é sua referência a uma vida sexual quase sempre deformada, que se fundamenta no comportamento de exceção, nos vícios e exageros eróticos”. Ou seja, para este autor, a grosseria é o resultado do gosto pelo obsceno e, por conseguinte, imbrica-se com o vocábulo gírio, já que estes termos parecem assumir o erotismo "como fonte criadora de novos significados" (p. 66).

\section{O VOCÁBULO GÍRIO}

Lendo o trabalho de onde extraí a epígrafe para este artigo, percebi uma denúncia de Azevedo (1973, p. 59), segundo a qual a literatura acerca da gíria, na época, não era tão ampla no Brasil, devido à "quase total inexistência de bibliografia" 5 . Mesmo assim, selecionando estudantes universitários e duas revistas de circulação nacional, se propôs a investigar o fenômeno denominado de "gíria dos jovens". Com este trabalho, a pesquisa objetivava "localizar a gíria da juventude brasileira",

\footnotetext{
${ }^{5}$ O que não se sustenta mais em nossos dias, já que Preti (2000), ao analisar as "transformações do fenômeno sociolingüístico da gíria", registra "um número considerável de pesquisadores e curiosos que se dedicaram a recolher os vocábulos" [gírios] (p. 213). Para maiores detalhes, ver Preti (2001), onde o autor realiza uma espécie de estado da arte sobre a temática, enfocando especificamente o vocábulo gírio, associando-o à história do preconceito social.
}

ARAÚJO - Chats na web... 
objetivo que, a meu ver, era muito ambicioso na medida em que um estudo deste porte, além de requerer muito tempo para o exame do corpus, reduziu muito o quadro dos informantes da pesquisa, o que desemboca em um problema metodológico: a delimitação. Em acréscimo a isso, há o fato de o trabalho conferir o status de língua ao vocábulo gírio, já que gíria e língua são postos no mesmo par de igualdades. Acerca do assunto, Preti (2000, p. 218) afirma que "a gíria constitui um vocabulário (não uma língua, porque não tem sintaxe)".

Por outro lado, é preciso considerar a data em que a pesquisa de Azevedo foi realizada, para entender a razão de nela existirem as incongruências acima, dentre as quais ainda se pode apontar a confusão entre a gíria e a linguagem das profissões. De acordo com o texto em questão, "há uma gíria dos médicos, dos advogados, dos engenheiros" (p. 62), entre outras profissões. Mas, à luz dos estudos sociolingüísticos contemporâneos, isto não se sustenta mais na medida em que se vislumbra um consenso entre os estudiosos da área de que a linguagem referente a profissões constitui um jargão, e não uma gíria. Deste modo, é possível falar na existência de um jargão médico ou de um jargão dos advogados, por exemplo.

Sobre esse assunto, Preti (2001) assegura que a confusão que alguns autores fazem acerca da terminologia gíria/jargão pode ser resolvida se se considerar que o rótulo jargão faz referência a uma linguagem "técnica banalizada" e obscura, como o jargão médico. Por esse motivo, o eixo definidor de gíria que adoto neste artigo é iluminado pela ótica de Preti (1983), para quem há dois tipos de gírias: a gíria de um grupo e a gíria comum.

A primeira, também designada de signo de grupo, pode estar associada ao que o autor denomina de linguagem proibida, visto que esta se relaciona com a vida e a cultura de grupos herméticos e, por isso mesmo, assume uma função de preservação e defesa desses grupos. Preti (1983) assevera que, pela gíria, esses grupos demonstram sua visão e julgamento da sociedade que os marginaliza. Esta é a razão pela qual o vocábulo gírio é acessível apenas a uma minoria. Na seqüência, disponibilizo uma figura que elaborei a partir de um outro trabalho de Preti (2000), a qual mostra alguns dos grupos que o autor aponta como usuários de gírias. 


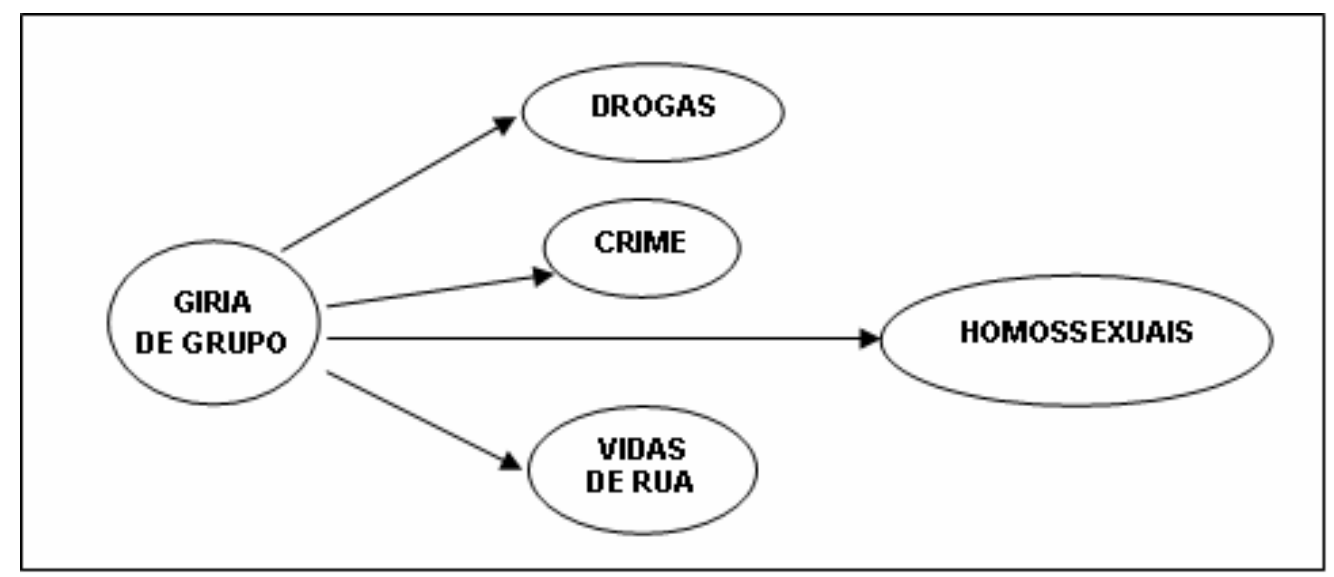

Figura 1 - Grupos usuários de gíria.

Tentei demonstrar, por esta figura, o modo pelo qual Dino Preti entende a gíria de grupo. Apesar de concordar com algumas de suas idéias, é possível perceber nelas um grande problema metodológico: o da delimitação, pois delimitar um grupo usuário de gíria não é uma tarefa simples. Penso que nunca poderemos enquadrar o sujeito em "gaiolas classificatórias" como fazemos com determinados objetos, uma vez que ele e a sociedade que o constitui gozam da mesma dinamicidade. Mas esta problemática não passa despercebida por Preti (1983, p. 66), pois ele afirma que "uma das dificuldades com que nos deparamos ao analisar esse problema é a de delimitar o campo do fenômeno gírio, dentro da linguagem popular". Não obstante, é constatável na figura 1 que um grupo, como o designado pelo rótulo "drogas" é extremamente amplo. Por isso, é possível fazer ilações acerca de possíveis subgrupos, tais como o grupo dos traficantes, o grupo dos viciados, o grupo dos que buscam apoio em clínicas etc.

Julgo que o mesmo raciocínio se aplica aos grupos "crime" e "vidas de rua", os quais podem ser confundidos com o grupo "drogas" se for levado em conta, por exemplo, o contexto sócio-espacial em que tais grupos se inserem. Considero ainda mais complexo identificar uma gíria homossexual, posto que este grupo, assim como os demais, não se mostra homogêneo, como sugere a figura 1. Entre outros, existem, por exemplo, homossexuais travestis, que muitas vezes são associados à prática da protistuição, e aqueles que se autodenominam transformistas, e que realizam shows em casas noturnas. Certamente, as escolhas lingüísticas de cada uma dessas organizações sociais se apresentarão 
distintas entre si, embora todas denotem o modo pelo qual esses grupos se auto-identificam.

Ainda de acordo com o artigo publicado em 2000 (p. 223), Preti mostra um segundo tipo de gíria, por ele nomeada como gíria comum ${ }^{6}$. Recebe este nome porque se trata do resultado da transposição da gíria de grupo para o contexto da linguagem comum. Assim, ao sair do âmbito do grupo fechado, a gíria perde sua característica de "signo de grupo", forçando a criação de outras palavras. Por esta razão, "a perda da condição de signo de grupo faz com que os falantes dos grupos restritos procurem outros vocábulos que voltem a constituir desafios para a compreensão do falante comum".

Entendo o grupo restrito como um conjunto de indivíduos que elaboram objetivos comuns para a sobrevivência do coletivo, e não do individual. Veja-se o caso do grupo de traficantes de drogas que, para sobreviver, cria verdadeiros "dribles lingüísticos" a fim de fugir à ameaça da polícia. Entretanto, o agrupamento que se forma entre pessoas desconhecidas, nos reality shows e nas salas chats, por exemplo, parece regido por outra fórmula, a do "cada um por si". O importante ali é deixar que o olhar eletrônico filtre uma imagem que seduza os telespectadores, no caso dos primeiros, a fim de ser o escolhido para ganhar o cobiçado prêmio em dinheiro. Portanto, a translocação de certos agrupamentos para outros contextos parece ter, atualmente, o poder de dissolver a idéia original de grupo restrito e com ela o seu léxico.

Esta discussão parece razoável, uma vez que os grupos sociais aos quais Preti se refere são formados por pessoas que se juntam por algum fenômeno social comum, como a orientação sexual, a religião, o papel na sociedade, a faixa etária, a atividade exercida. No caso dos participantes dos reality shows, não existe nenhum traço que possibilitaria a formação de um grupo social, pois o que une aquelas pessoas é a vontade de ganhar dinheiro e se tornar celebridade "meteórica", fato que dificilmente proporcionaria a existência de um signo de grupo entre eles. Pelo

\footnotetext{
${ }^{6}$ Em seu trabalho de 2001 (p. 246), Preti mostra que a gíria comum também se vincula a grupos específicos, como a gíria do futebol, dos estudantes etc. A diferença entre estes grupos e os grupos apresentados no quadro acima reside no fato de que os últimos utilizam uma gíria de defesa e preservação, e os primeiros assumem "uma feição mais lúdica, [e apresentam uma] maior interação com a grande comunidade".
} 
contrário, cada um mantém a linguagem de seu grupo de origem, gerando uma geografia lingüística que é flagrada e publicada em cadeia nacional pelas câmeras.

Isto me leva a considerar a existência de práticas discursivas que se pautam por "contratos lingǘsticos" capazes de dissolver o que se poderia considerar de linguagem proibida. Assim considerou Guilbert (1975), em relação ao fenômeno da dicionarização e Komesu (2005), quanto à publicização do íntimo nos reality shows e nos blogs. Será nesta esteira que defendo o mesmo aqui em relação aos chats, conforme a discussão que se segue.

\section{METODOLOGIA}

Ao tomar como base a discussão dos itens anteriores, creio que posso agora justificar a minha opção metodológica. Em primeiro lugar, não irei discutir o vocábulo gírio em seu sentido stricto, uma vez que há dificuldades, como mostrei, para delimitar um determinado grupo. Considero que o processo de delimitação fica ainda mais complexo quando o que se pretende estudar possui um caráter amplo, como as salas de chat. São incontáveis os tipos de pessoas que "freqüentam" as famosas salas de bate-papos virtuais na Internet.

Para a análise, reuni dados relativos a vários tipos de sala de chat do UOL (cidades e regiões; por idade; tema livre e variados) ${ }^{7}$, coletando duas sessões de cada sala no periodo de dois domingos do mês de julho de 2001, totalizando 8 sessões. Ainda que tais salas se organizem em diversas categorias temáticas, como cidades e regiões, adolescentes, sexo, política etc., percebi que não é seguro pensar que cada uma hospeda um grupo homogêneo e que tenha desenvolvido uma linguagem peculiar a ponto de reivindicar o status de "signo de grupo"8. Em face disto, o que passarei a mostrar, subseqüentemente, é como o locus do chat permite o livre uso de determinadas escolhas lingüísticas que,

\footnotetext{
${ }^{7}$ Esses eram alguns dos nomes das salas do UOL, na época da construção dos dados.

${ }^{8}$ Não quero dizer com isto que inexistam grupos fixos em uma sala de chat, eu mesmo estudei um destes em minha Dissertação de Mestrado (ARAÚJO, [2003] 2005a), no entanto, dada a natureza deste tipo de interação, posso afirmar que a existência de tais grupos é rara.
}

ARAÚJO - Chats na web... 
ditas/escritas ou ouvidas/lidas em um outro espaço social de comunicação, seriam tidas como vocábulos gírios, grosseiros, obscenos e blasfêmicos, seja qual for a categoria que se queira dar às ocorrências.

Analiso, inicialmente, os enunciados dos chatters, focalizando aqueles que, durante a leitura do corpus, mais me chamaram a atenção. Em um segundo momento, atenho-me aos nicknames utilizados pelos chatters nas sessões coletadas.

\section{CARACTERIZAÇÃO DA LINGUAGEM PROIBIDA NOS CHATS}

Durante o período de realização desta pesquisa, o UOL era o provedor brasileiro que mais disponibilizava tipos diversificados de salas de chat. Poder-se-ia pensar que cada tipo de sala desenvolve uma linguagem peculiar, mas os dados mostram que a natureza conversacional e técnica dos softwares permite que "a Internet [seja vista] como o lugar em que todos os dizeres são possíveis, já que o anonimato seria a garantia da preservação jurídica do sujeito" (KOMESU, 2005, p. 56). Por essa razão, esse espaço não apenas transmuta os gêneros de outras esferas (cf. ARAÚJO, 2006), mas atinge aspectos como a capacidade humana de dissimular os preconceitos, o erotismo escancarado, a obscenidade e tudo mais que possa caracterizar o que é considerado proibido pela sociedade (cf. SIQUEIRA, 2005). Vejamos o exemplo subseqüente.

\section{Exemplo 1}

1. (00:43:14) n@veg@ador grita com TODOS: O FERNANDO TÁ CONSEGUINDO, TÁ CONSEGUINDO ACABAR COM O POKO K NOS RESTA

2. (00:44:19) kôkô flerta com n@veg@ador: to kgando pro viajando $\mathrm{H}$ kardoso

O diálogo acima se constitui por uma linguagem carregada de índices coloquiais, o que denota uma grande liberdade de expressão. No turno enviado pelo internauta de nickname n@veg@dor, é possível 


\section{4}

verificar a maneira íntima como o usuário se refere ao ex-presidente da república, Fernando Henrique Cardoso. Evidentemente, o locus e o anonimato que o seu apelido lhe confere permitem mobilizar uma linguagem que não é a convencional, comumente usada para se referir a uma autoridade como o Presidente da República. Falta, por exemplo, o pronome de tratamento ou qualquer outro índice que indique a referência mais adequada, dentro desse registro, à pessoa do Presidente. Portanto, estaríamos diante de uma grosseria se esta ocorrência acontecesse em outra situação que não fosse numa interação em sala de bate-papo virtual.

No turno 2 do exemplo acima, a irreverência começa pelo nickname escolhido pelo usuário. A alcunha deste internauta e a expressão "kgando" permitem a interpretação, à luz do que defende Preti (1983), como casos explícitos de obscenidade e grosseria, visto que a incidência recai sobre o escatológico. Além disso, a expressão "viajando $\mathrm{H}$ kardoso" remete-nos ao programa humorístico "Casseta \& Planeta Urgente", da TV Globo, o qual também veicula, livremente, uma linguagem proibida. Durante o período do governo FHC, ao aproveitar a terminação -ando, os humoristas passaram a fazer o uso de verbos no gerúndio para se referir ao então presidente Fernando Henrique Cardoso. Desta maneira, era comum escutar, por exemplo, a expressão "Visitando Henrique Cardoso" para noticiar as chegadas das viagens internacionais que o presidente fazia, denotando que ele apenas "visitava" o país que governava.

Tal como mostra o exemplo 1, não há a ocorrência de nenhum índice lexical que permita estudar a linguagem utilizada nesta sala como um signo de grupo, como, por exemplo, um grupo de internautas que se "reúne" para bater-papo sobre política. Provavelmente, estes mesmos sujeitos migrarão para outras salas de categorias temáticas diferentes e, certamente, continuarão a fazer uso de vocábulos de natureza proibida para discutirem outro assuntos, como se verá na seqüência.

Além da informalidade e do escatológico, o "lugar virtual de fala" assumido pelos chatters (cf. ARAÚJO, 2005b) permite o uso de recursos vários para substituir expressões que denotem apelo sexual, como se 
evidencia no exemplo retirado de uma sala de chat da categoria cidades e regiões ${ }^{9}$ do UOL.

\section{Exemplo 2}

1. (23:15:18) A vilã FREIRA $\backslash \sim /{ }^{\circ}$ grita com $\mu$ aterial Girl $\mathbb{R}:$ Tu qr é chupar os pirulitos deles :-D

2. (23:15:24) 50tãofogoso grita com TODOS: naum sou daqueles q gostam de se acabar na maum... prefiro ir lá e lamber na fonte.

Vibro qdo uma cachorra me faz gozar

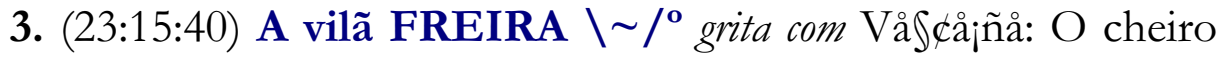
dakilo é quiboa ou d leite azedo?

4. (23:15:46) VåScåañå grita com A vilã FREIRA $\backslash \sim /{ }^{\circ}$ : NAUM.. É XERO DE GALA MERMO..

Para analisar esse exemplo, convém citar o relevante trabalho de Monteiro (1986) que, em seu artigo sobre "as palavras proibidas", à luz da sociolingüística, examina os limites do místico que ronda a linguagem, uma vez que os usuários, tal como ele demonstra, imprimem um valor místico em determinadas palavras. Para dar conta dessa discussão, Monteiro apresenta e analisa alguns índices lingüísticos, como a adulteração fonética dos vocábulos, o emprego de sinônimos ou, ainda, o uso de dêiticos para evitar a pronúncia de certos nomes referentes a doenças ou a pessoas das quais não gostamos. Alguns exemplos que são dados pelo autor, na ordem dos índices que elenquei acima são "pequepê"; "vá pra ponte que caiu"; "diacho"; "aquela (doença)", entre outros. De acordo com Monteiro, ao mobilizar esta pluralidade de artifícios, os usuários da língua acreditam poderem neutralizar o misticismo das palavras proibidas.

Voltando para o exemplo 2, verifica-se que os sinônimos e os dêiticos não assumem uma função atenuadora, como em Monteiro (1986), mas querem, exatamente, reforçar o sentido do proibido. Deste modo, as expressões "chupar pirulito" e "lamber na fonte" (turnos 1 e 2 ) são usadas para denotar sexo oral, assim como a expressão "se acabar na maum" (turno 1) substitui a expressão "se masturbar". A mesma função

\footnotetext{
${ }^{9}$ No caso, trata-se da sala 1 de Fortaleza.
} 
assume o vocábulo "gala" (turno 4) que se refere ao termo "esperma". Percebe-se que os dêiticos "lá" e "dakilo", respectivamente, turnos 2 e 3 , também não são usados como índices atenuadores, mas como marcas indicadoras de um livre uso da linguagem proibida. Enquanto o primeiro dêitico se refere ao ato sexual, o segundo denota o sentido atribuído a esperma. Pode-se observar ainda, no turno 2 , o uso de um vocábulo grosseiro, quando o chatter 50tãofogoso reduz a figura da mulher a uma fêmea da espécie canina no cio, o que retoma uma prática machista de nossa sociedade, a qual costuma usar vocábulos grosseiros para se referir à mulher de forma depreciativa. Além disso, é importante observar também o ato ilocutório grita com selecionado pelo internauta (cf. MARCUSCHI, 2004), pois simula o material fônico que caracteriza esse tipo de linguagem proibida.

Além dos sinônimos e dos dêiticos, os internautas lançam mão de outras linguagens com o mesmo objetivo. É o caso do uso de imagens que aparecem, em sua maioria, com função tautológica nos turnos. O turno 2 , do exemplo acima, apresenta esta imagem $\bullet$, como se quisesse demonstrar facialmente o orgasmo sexual. Isto fica perfeitamente demonstrado pelo uso da semiose verbal, cujo sentido é reforçado pela imagem. Do mesmo modo, o turno 4 exibe esta outra imagem representando uma "camisinha" usada. Basta que se leia o que a internauta "teclou", para que logo se perceba a função tautológica dessa imagem em seu turno.

Além disso, é perceptível o uso dos emoticons. No turno 1, verificase que há uma combinação dos dois pontos, do hífen e da letra maiúscula $\mathbf{D}$, para denotar uma "carinha com a língua de fora". O que se observa é que a redundância que se instaura entre o que está escrito e o que representa o emoticon não é gratuita, mas uma estratégia discursiva de acentuar o uso da linguagem proibida no chat, embora esse mesmo ícone de emoção possa ser usado para demonstrar um gesto carinhoso em um outro contexto. Ainda nos turnos 1 e 4 , anexado ao nick A vilã FREIRA $\backslash \sim /^{\circ}$, observa-se o uso de um emoticon, o qual pode ser compreendido como um cálice, dado o contexto e o conteúdo semântico do apelido.

Nesse sentido, a inteligente combinação de caracteres do teclado do computador também revela um uso de uma linguagem proibida. Vejase que o apelido da interagente menciona religiosidade no vocábulo 
freira. No entanto, o adjetivo vilã e o referido emoticon assumem a função dessacralizadora, pois pode-se depreender daí duas leituras. A primeira seria a de uma bacante disfarçada de freira, por isso o adjetivo vilã. A segunda leitura pode remeter para um dos símbolos mais caros à fé católica: a eucaristia. Observa-se que o til entre as duas barras opostas, indicando o líquido, e a letra $\mathbf{O}$, indicando uma rodela de limão, demonstram, no sentido benvenisteano do termo, uma blasfêmia difamante, uma vez que pode haver uma alusão ao rito eucarístico da transubstanciação, em que o vinho se transforma no sangue de Cristo, conforme prega a fé católica.

Se "para um cristão, por exemplo, é uma blasfêmia dizer que o pão e o vinho simbolizam o corpo de Cristo, pois, para ele, eles o são verdadeiramente" (FIORIN, 1995, p. 9), imagine-se, pois, reduzir o cálice consagrado a um drink, cuja imagem representa uma taça com uma rodela de limão na borda. Todos sabem que se aderir ao gesto de pôr uma rodela de limão na borda do cálice consagrado, o sacerdote ou qualquer outro representante legítimo da Igreja estaria assumindo uma atitude blasfêmica, uma vez que haveria uma banalização do rito religioso. Seja o simples fato de a transubstanciação ser equiparada ao status de símbolo, seja a atitude de pôr uma rodela de limão na borda do cálice consagrado, tudo é interpretado pelos valores e fé católicos como um ato de genuína blasfêmia.

Outro índice relevante de como os tabus lingüísticos parecem se dissolver em ambiente digital é o nickname. Sobre esse fenômeno, ao estudar o fórum eletrônico, Xavier e Santos (2005, p. 37) sinalizam para o fato de que a "informalidade e o pouco compromisso dos usuários principalmente com o como dizem e o que dizem, [deve-se] talvez por causa da certeza de que terão as suas verdadeiras identidades preservadas pelo artifício do pseudônimo". Seguindo este raciocínio, mostrei em Araújo (2007a, 2007b) que os nicknames podem ser elencados segundo o significado que denotam. Por isso, tais índices podem ser um bom exemplo de destabuização da linguagem proibida, já que os apelidos que os chatters utilizam para sua identificação nas interações virtuais, segundo Marcuschi (2004, p. 44), com quem concordo, "revela[m] uma importante faceta oculta de nossa sociedade contemporânea reprimida e que agora aflora no anonimato das salas de bate-papo". 
Ainda que, de acordo com Crystal (2001, p. 166), tal perspectiva pertença muito mais à Psicologia Social do que à Lingüística, esta maneira de organizar o estudo lingüístico acerca dos nicknames é defendida por esse autor. Sendo assim, fiz um levantamento estatístico no corpus usado para a escritura deste artigo, a fim de verificar como se dava a distribuição percentual dos nicknames que materializam algumas expressões-tabus (gráfico 1). Para isso, usei como categorias os nicks que denotavam principalmente o apelo no campo do erótico (17 ocorrências), do escatológico (8 ocorrências) e do blasfêmico (9 ocorrências).

De acordo com o número de ocorrências e suas representações percentuais no gráfico 1 , verifica-se que a preferência dos usuários incide em apelidos que denotem apelo erótico, corroborando o que afirma Preti (1983) acerca da estreita e forte relação entre o léxico e o erotismo, e, portanto, com o proibido. Em seqüência, verifiquei que há também uma preferência pelo blasfêmico e, finalmente, não em um percentual menos expressivo, encontrei apelidos que denotam apreço pelo vocábulo escatológico. O gráfico foi organizado com base no quadro 1, subseqüente, pelo qual o leitor pode ter acesso a todos os exemplos deste tipo de nicknames, separados para o presente estudo.

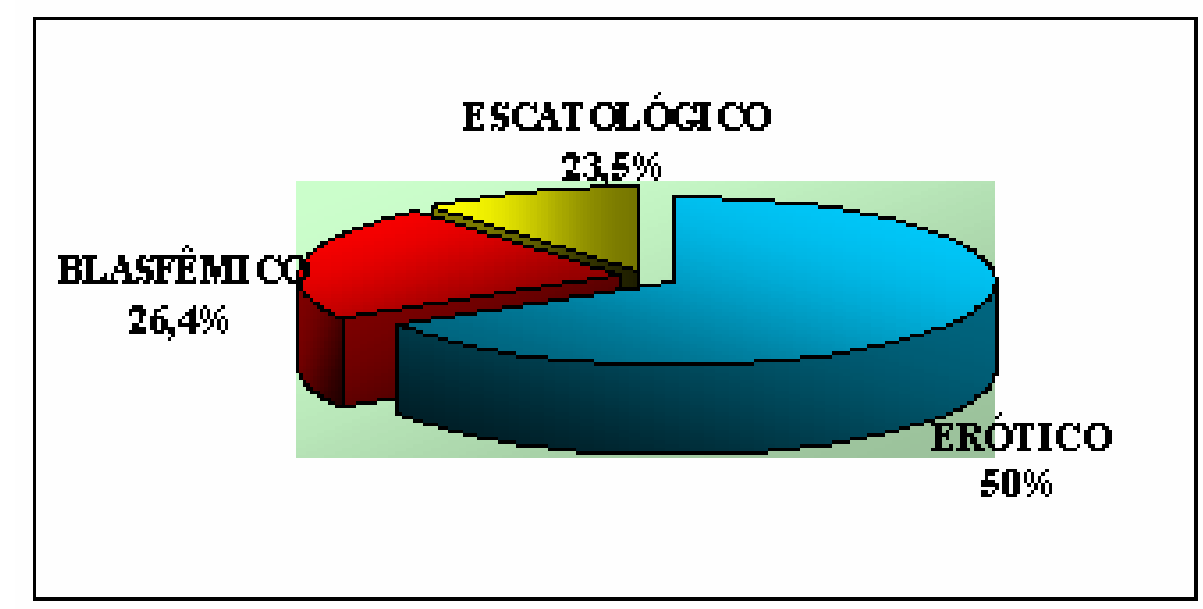

Gráfico 1 - Distribuição percentual dos usos dos nicknames.

O quadro mostra claramente que as motivações para compor os apelidos, do ponto de vista [para]lingüístico, são várias e, por isso, é possível encontrar, nos nicks, casos de homofonia, como 50tãofogoso; 
de junturas como VUMITUINTU [vomito em tu]; de composição por aglutinação e justaposição, como bucetnet e Webpeidaum, entre outros que o leitor poderá identificar no quadro 1.

\begin{tabular}{|l|l|l|}
\hline APELO ERÓTICO & APELO ESCATOLÓGICO & APELO BLASFÊMICO \\
\hline GUSM Oh Yesssssssss & Merdanopau & ar@anjo das trevas \\
\hline $\begin{array}{l}\text { PINTO GROSSO-13 } \\
\text { ANOS }\end{array}$ & VUMITUINTU & @njo negro \\
\hline Karasafado & Kôkô & a serviço do caum \\
\hline Tiagosex & lambedor de remela & katarro na + \\
\hline Filho da pauta & Webpeidaum & Kpta \\
\hline H x H & katarro pretu & sugador de alma \\
\hline Anaum de pau duro & Peidonet & Pedófilocristao \\
\hline gato quer sexo agora & mister arroto & A vilã FREIRA $\backslash \sim /^{\circ}$ \\
\hline Bucetnet & $-\mathrm{x}-$ & Pastor comeku \\
\hline Komekupri & $-\mathrm{x}-$ & $-\mathrm{x}-$ \\
\hline 50tãofogoso & $-\mathrm{x}-$ & $-\mathrm{x}-$ \\
\hline Putinha de botas & $-\mathrm{x}-$ & $-\mathrm{x}-$ \\
\hline ku-bataum & $-\mathrm{x}-$ & $-\mathrm{x}-$ \\
\hline 21cm de ferro & $-\mathrm{x}-$ & $-\mathrm{x}-$ \\
\hline PAU(l)inho & $-\mathrm{x}-$ & $-\mathrm{x}-$ \\
\hline Bruninha arrombadinha & $-\mathrm{x}-$ & $-\mathrm{x}-$ \\
\hline Safadinha cibernet & $-\mathrm{x}-$ & $-\mathrm{x}-$ \\
\hline
\end{tabular}

Quadro 1 - Os nicknames como denotadores de linguagem proibida.

\section{CONSIDERAÇÕES FINAIS}

A análise permite que se apontem algumas conclusões preliminares. Em primeiro lugar, a linguagem usada nas interações virtuais em sala de chat, independentemente da categoria temática das salas, não apresenta índices lexicais que permitam um estudo de signo de grupo, uma vez que não é simples delimitar um grupo restrito que se diferencie pelo uso de uma gíria que lhe seja peculiar. Assim sendo, essa translocação de grupo para outros ambientes não modifica somente o que seria considerado um tabu lingüístico, mas também a própria noção do que seja um grupo. Pensando nos reality shows, é fácil perceber que ali 
ocorre um agrupamento de pessoas, mas não um grupo, tanto é que eles não têm uma linguagem própria. Além do conceito de grupo ser transformado em função do jogo, os dados levantam a hipótese de que determinados ambientes contribuem para a queda de verdadeiros tabus lingüísticos, tal como também ocorre nos chats.

Assim, este estudo permite inferir que não há como designar o fenômeno aqui estudado como gíria comum, pelo simples fato de as ocorrências estarem sendo veiculadas pela Internet. Deste modo, acredito que seria mais adequado abrigar, sob o rótulo de linguagem proibida, todos os vocábulos que se associem à gíria, à obscenidade, à blasfêmia, ao palavrão, à grosseria, a fim de melhor caracterizar a queda de tabus pelo livre uso da linguagem "marginal" dos participantes de chats.

Os nicknames constituem a maior estratégia para a expressão do proibido nos bate-papos virtuais, graças ao anonimato que tais apelidos conferem aos chatters, de maneira que estes se sentem seguros para expressarem suas identidades, sejam reais, sejam fictícias. Estes apelidos se apresentam sob vários formatos (para)lingüísticos e denotam diferentes expressões tabuizadas com apelo ora erótico-blasfêmico, ora escatológico, ainda que o primeiro caso mostre mais expressividade percentual.

Os dados mostram que os tabus não assumem materialidade somente de caráter lingüístico, pois os internautas operam com outras linguagens, como a imagética e os emoticons, imprimindo nos textos conversacionais um caráter multissemiótico. Finalmente, tanto os emoticons, quanto as imagens e o uso de dêiticos e sinônimos não representam estratégias de suavizar o tom proibido. O objetivo dos sujeitos é intensificar a referência a uma linguagem proibida, sendo que tais recursos poderiam ser entendidos como tautologia, se não assumissem uma importante função enfática nesses gêneros digitais.

Enfim, todos os índices aqui mostrados comprovam a suposição que levantei para este estudo, segundo a qual o locus das interações via chats, pelo menos por enquanto, não apresenta nenhuma censura, muito menos ameaças de sansões coercitivas para quem ultrapassar a barreira do 'proibido'. Concluo, deste modo, que, como analisa Benveniste ([1974] 1989), se há palavras que não pode passar pela boca, no chat 
todas, sem exceção, podem "passar pelos dedos", basta que se digite ou se opere com algum recurso paralingüístico para expressar o "proibido".

\section{REFERÊNCIAS}

ALMEIDA, N.; ZAVAM, A. Variação lingüística: uma questão de sala de aula. In: __ (Orgs.). A língua na sala de aula: questões práticas para um ensino produtivo. Fortaleza: Perfil Cidadão, 2004. p. 237-267.

ARAGÃO, M. S. S. Aspectos sêmio-fonéticos da música de forró. In: AGUILERA, V. (Org.). Diversidade fonética no Brasil: pesquisas regionais e estudos aplicados. Londrina: UEL, 1997. p. 77-89.

ARAÚJO, J.C. Chat na Web: um estudo de gênero hipertextual. In: CAVALCANTE, M. M.; BRITO, M. A.; MIRANDA, T. P. (Orgs.). Teses \& dissertações: Grupo Protexto. V. 1. Fortaleza: Protexto; UFC, 2005a [2003]. [Cd-Rom].

. Chat educacional: o discurso pedagógico na Internet. In: COSTA., N.B. (Org.). Práticas discursivas: exercícios analíticos. Campinas, SP: Pontes, 2005b. p. 95-109.

Os chats: uma constelação de gêneros na Internet. Tese (Doutorado em Lingüística) - UFC, PPGL, Fortaleza, 2006.

"Kd a roupinha do nick?": brincando de vestir identidades no chat aberto. In: COSTA, M. F. V.; COLAÇO, V.F.R.; COSTA, N.B. (Orgs.). Modos de brincar, lembrar e dizer: discursividade e subjetivação. Fortaleza: Edições UFC, 2007a. p. 189-204.

. Nicks \& emoticons no chat aberto: uma análise da ressignificação da escrita. In: CAVALCANTE, M. M. et al. Texto e discurso sob múltiplos olhares: gêneros e seqüências textuais. v.1. Rio de Janeiro: Lucerna, 2007b. p.38-61.

AZEVEDO, C. C. A jovem gíria dos jovens. Monografia (Graduação em Letras) - Pontifícia Universidade Católica de Rio Grande do Sul (Puc-Rs), Instituto de Letras e Artes, Porto Alegre, 1973.

BENVENISTE, E. A blasfêmia e a eufemia. In: Problemas de lingüística geral II. Tradução de Ingedore G. Villaça Koch. São Paulo: Pontes, 1989 [1974]. p. 259-262. 
CRYSTAL, D. Language and the Internet. Cambridge: Cambridge University Press, 2001.

FIORIN, J. L. As astúcias de enunciação: as categorias de pessoa, espaço e tempo. São Paulo: Ática, 1995.

FONSECA, L. O uso de chats na aprendizagem de línguas estrangeiras.

Caligrama, v. 7, p. 101-121, 2002.

GUILBERT, L. La creativité lexicale. Paris: Larousse, 1975.

GUIRAUD, P. Les gros mots. Paris: PUF, 1976.

KOMESU, F. Entre o público e o privado: um jogo enunciativo na constituição do escrevente de blogs da Internet. Tese (Doutorado em Lingüística) - Unicamp, IEL, Campinas, 2005.

MARCUSCHI, L. A. Gêneros textuais emergentes no contexto da tecnologia digital. In: _ _ XAVIER, A. C. (Orgs.). Hipertexto e gêneros digitais: novas formas de construção de sentido. Rio de Janeiro: Lucerna, 2004. p. 13-67.

MONTEIRO, J. L. As palavras proibidas. Revista de Letras, v. 11, n. 12, p. 11 23, Jul./Dez. 1986.

PRETI, D. A linguagem proibida: um estudo sobre a linguagem erótica. São Paulo: T.A. Queiroz, 1983. 93-99, 1992.

As transformações sociais e seu reflexo no léxico. Confluência, n. 4, p. Transformações do fenômeno sociolingüístico da gíria. Revista da Anpoll, n. 9, p. 213-226, Jul./Dez. 2000.

- A gíria na língua falada e na escrita: uma longa história de preconceito social. In: PRETI, D. (Org.). Fala e escrita em questão. 2. ed. São Paulo: Humanitas, 2001. p. 241-257.

SIQUEIRA, K. A. de. Cenas de racismo explícito: o discurso racista no fórum virtual. In: COSTA, N.B. (Org.). Práticas discursivas: exercícios analíticos. Campinas, SP: Pontes, 2005. p. 127-136.

XAVIER, A. C.; SANTOS, C. F. E-fórum na Internet: um gênero digital. In: ARAÚJO, J. C.; BIASI-RODRIGUES, B. (Orgs.). Interação na Internet: novas formas de usar a linguagem. Rio de Janeiro: Lucerna, 2005. p. 30-38.

Recebido em 18/03/08. Aprovado em 15/06/08. 
Title: Chats on the web: forbidden language and taboo-breaking

Author: Júlio César Araújo

Abstract: This paper discusses the assumption that forbidden language and its associated taboos are dissolved when it comes to the digital environment of chats. The discussion is based on the sociolinguistic perspective of Dino Preti (1983; 1992; 2000; 2001), and on the enunciative perspective of Benveniste ([1974] 1989). These perspectives were chosen since they help in the analysis of extracts of interaction via chat, taking into consideration words associated with slang, obscenity, blasphemy, swearing and rudeness, used both in the chatters' nicknames and in their conversations. The data analysis indicates that the non-identification of participants through the use of their nicknames is one of the most productive elements to the "free" use of marginal language, which is not only restricted to the limits of verbal language, but also to other semioses employed by the users.

Keywords: interaction; internet; chat; linguistic taboo.

Titre: Chats dans Web: le langage interdit et la chute des tabous

Auteur: Júlio César Araújo

Résumé: Dans cet essai, je discute la supposition concernat le fait que le langage interdit et les tabous qui lui sont associés se dissolvent au moment d'entrer dans l'ambiance des chats. La discussion est guidée par les perspectives sociolinguistiques de Dino Preti $(1983$; 1992 ; 2000 ; 2001) et énonciative de Benveniste ([1974] 1989), une fois que ces travaux aident ici à analyser des fragments d'interaction par l'intermédiaire des chats, considérant, dans ce cas, les mots qui s'associent aux mots d'argot, à l'obscenité, à la blasphème, aux gros mots et à la grossièreté, soient utilisés dans les nicknames des internautes ou dans la conversation. L'analyse des fragments permet de conclure que l'anonymat accordé aux participants, qui se servent de surnoms, se montre comme l'un des facteurs plus productifs pour le «libre» emploi du langage marginal, lequel paraît être circonscrit non seulement aux limites du verbal, mais aussi à d'autres sémioses employés par les usagers.

Mots-clés: chat; tabou linguistique; interaction linguistique; internet.

Título: Charlas en la Web: el lenguaje prohibido y a queda de tabúes

Autor: Júlio César Araújo

Resumen: En este ensayo, discuto la suposición de que el lenguaje prohibido y los tabúes a ella asociados se disuelven cuando entran al ambiente digital de las charlas. La discusión es guiada por las perspectivas sociolingüísticas de Dino Preti (1983; 1992; 2000; 2001) y enunciativa de Benveniste ([1974] 1989), una vez que esos trabajos ayudan aquí a analizar fragmentos de interacción vía chat, siendo, en este caso, considerados los vocablos que se asocian al lunfardo, a la obscenidad, a la blasfemia, a la mala palabra y a la grosería, sean ellos utilizados en los apodos de los internautas o en la conversación. El análisis de los fragmentos permite concluir que el anonimato conferido a los participantes, a través de sus apodos, se muestra como uno de los factores más productivos para el "libre" uso del lenguaje marginal, el cual parece estar circunscrito no solamente a los límites de lo verbal, sino también a otras semiosis 
334

utilizadas por los usuarios.

Palabras-clave: charla chat; tabú lingüístico; interacción lingüística; internet. 